23

\title{
Оконные оптические микроструктуры (обзор)
}

\author{
(C) В.А. Майоров \\ Новгородский государственный университет имени Ярослава Мудрого, \\ 173003 Великий Новгород, Россия \\ e-mail: Vitaly.Mayorov@novsu.ru
}

Поступила в редакцию 08.04.2020 г.

В окончательной редакции 08.04.2020 г.

Принята к публикации 04.05.2020 г.

\begin{abstract}
Выполнены обобщение и анализ результатов исследований по разработке и применению оптических элементов, размещаемых в верхней части окна с целью перенаправления солнечного света на потолок и вглубь помещения. Отмечена устойчивая тенденция перевода таких устройств на микроуровень. Приведено описание конструкций и оптических характеристик трех видов встроенных в стеклопакеты оптических микроструктур: микропризматических пленок, панелей с призматическими микроструктурами на двух сторонах, пленок с внедренными микрозеркалами. Отмечено, что использование в микроструктурах искривленных поверхностей вместо плоских улучшает оптические свойства и повышает равномерность потока перенаправляемого солнечного света. Обобщены конструкции и свойства оптических микроэлектромеханических систем - переключаемых микрозеркал и микрожалюзи, - изготавливаемых по технологии микроэлектроники.
\end{abstract}

Ключевые слова: окна, оптические микроструктуры, перенаправление солнечного света.

DOI: $10.21883 /$ OS.2020.10.50032.131-20

\section{Введение}

Боковое естественное освещение через окна в стенах является основным способом освещения общественных и жилых помещений.

Стандартные окна имеют существенные недостатки.

1. При прямом солнечном свете освещенность чрезмерно велика у окна, быстро уменьшается по мере удаления от него и в глубине помещения освещенность недостаточна.

2. Окно не устраняет яркий свет, ослепительный блеск („glare“) - блескость. Блескость - это визуальные условия с чрезмерной яркостью или высокой неравномерностью распределения яркости в поле зрения.

Способ устранения этих недостатков предлагает сложившееся к началу XXI века представление о комплексной конструкции бокового окна [1]. Комплексное окно состоит из двух частей (рис. 1).

1. Верхняя часть - часть естественного освещения - перенаправляет солнечный свет на потолок и в глубину помещения. Нижняя ее кромка расположена выше глаз стоящего человека в помещении $(1.8 \mathrm{~m})$, что позволяет избежать попадания перенаправленного света в глаза.

2. Нижняя часть - смотровая - обеспечивает визуальный контакт с окружающей средой (просмотр наружу), а также устраняет блескость на рабочей поверхности около окна.

К началу XXI века для перенаправления солнечного света было предложено три вида размещаемых в верхней части окна оптических элементов - призматические панели, надрезанные лазером панели и перена- правляющие солнечный свет устройства LUMITOP ${ }^{\circledR}[1]$. Эти устройства обладают рядом недостатков, обусловленных их значительной массой и габаритами. С начала XXI века выполняются непрерывные исследования и разработки по совершенствованию оконных оптических устройств. Основное направление - уменьшение их размеров, миниатюризация с переходом на микроуровень.

Уменьшение размеров оптических структур не изменяет оптических свойств и позволяет избежать отклонения от законов геометрической оптики (дифракции) до тех пор, пока их размеры не достигают диапазона длины волны видимого света. Оптические микроструктуры определяются как поверхностные структуры с поперечными и глубинными размерами порядка 10-1000 $\mu \mathrm{m}$. Перевод оптических структур на микроуровень облегчает их внедрение в окна и уменьшает вызываемое ими визуальное воздействие.

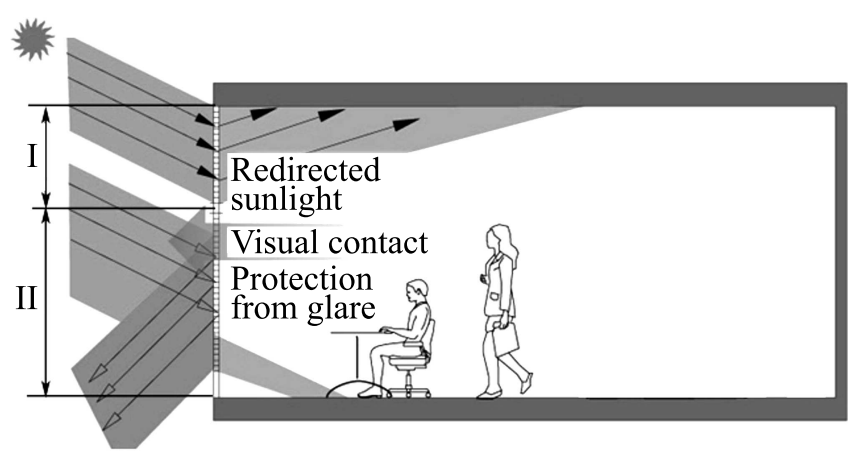

Рис. 1. Комплексное окно с различными функциями верхней I и нижней II частей. 
В предлагаемой работе приведен анализ выполненных за последние 20 лет исследований по разработке и применению оконных оптических микроструктур. Основное направление разработок заключается в миниатюризации существовавших оптических устройств, поэтому логично проследить тенденцию изменения свойств оптических устройств по мере уменьшения их размеров. Такие микроструктуры используют для перенаправления солнечного света и их размещают в верхней части окна.

\section{1. Призматические микроструктуры}

1.1. Призматические панели. Призматические панели для перенаправления солнечного света в глубину помещения предлагали использовать еще в начале XX века. Однако сложность изготовления таких изделий из стекла и наступившая эпоха искусственного электрического освещения похоронили эту технологию. Энергетический кризис 70-х годов и наличие доступного полиметилметакрилата (ПММА) вызвали второе рождение призматических панелей в конце XX века. Подробный анализ выполненных исследований по расчету и использованию трехгранных призматических панелей в устройствах естественного освещения выполнен в работе [2].

Призматическая панель - это пластина с горизонтальными призматическими ребрами (рис. 2). Свойства трехгранной призматической панели определяются углами $\alpha, \beta$ наклона граней. Солнечный свет преломляется на поверхности призмы и изменяет направление. Предельный угол наклона к горизонту $\theta_{1}^{*}$ отделяет проходящие сквозь панель солнечные лучи $\left(c-c^{\prime}\right)$ от лучей $\left(d-d^{\prime}\right)$, которые отражаются от нее за счет полного внутреннего отражения на тыльной поверхности.

Призматические панели изготавливают из ПММА литьем в форму. Готовое изделие устанавливается в герметичный стеклопакет. Призматические панели применяются для двух целей:
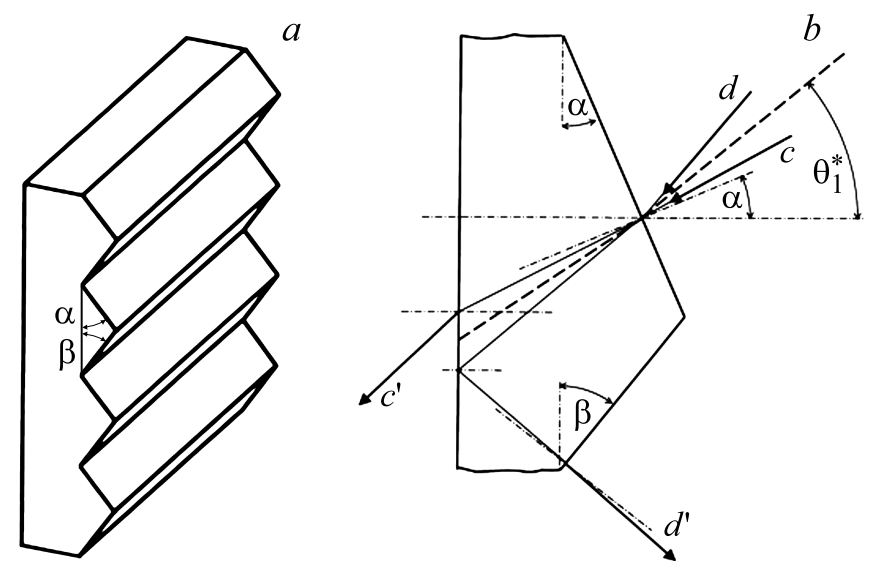

Рис. 2. Панель с трехгранной призматической структурой $(a)$ и направление солнечных лучей, проходящих сквозь панель $\left(c-c^{\prime}\right)$ и отраженных ею $\left(d-d^{\prime}\right)(b)[2]$.
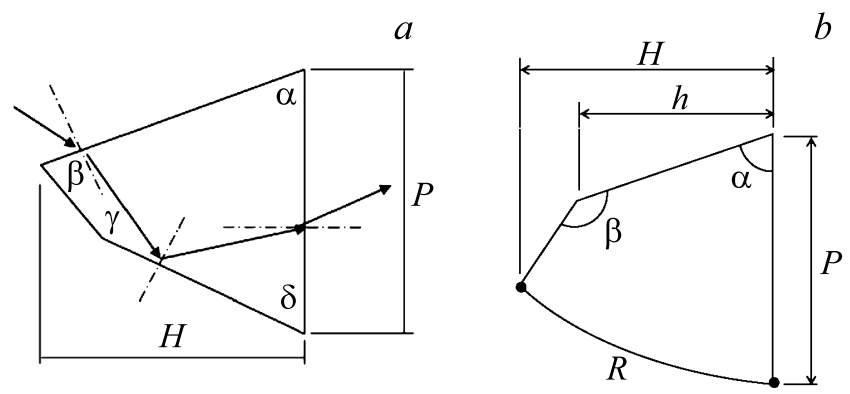

Рис. 3. Форма и основные геометрические характеристики четырехгранных микропризм: тип $1-$ с плоскими гранями $(a)$; тип $2-$ модифицированная с искривленной одной гранью (b) [6].

- для защиты от прямого солнечного света их размещают в фонарях на крышах;

- для изменения направления солнечного света их устанавливают в окнах.

Углы наклона граней определяются с учетом места размещения панели. При установке стеклопакета с призматическими панелями в фонарях верхнего света на одну из граней призмы наносится зеркальное отражающее покрытие методом вакуумного напыления алюминия [3]. Подбором углов наклона граней призматической панели можно добиться необходимого соотношения между долями проходящего и отраженного света.

Лидирующие позиции в изготовлении трехгранных призматических панелей для систем естественного освещения занимает немецкая компания Siteco Beleuchtungstechnik GmbH [3]. Стоимость призматических панелей (без стеклопакетов) составляет порядка 200 euro $/ \mathrm{m}^{2}$.

1.2. Микропризматические пленки. Микропризматическую пленку впервые разработала группа исследователей в Тайване в 2010 г. [4-6]. Изготовлено два типа микропризматической структуры (рис. 3). Структура типа 1 имеет четырехгранную форму высотой профиля $H=50 \mu \mathrm{m}$ и шагом $P=50 \mu \mathrm{m}, \alpha=45^{\circ}$. У модифицированной структуры типа 2 одна грань искривленная. Призма четырехгранная, две высоты $H=21.2 \mu \mathrm{m}$, $h=20 \mu \mathrm{m}$, шаг $P=18 \mu \mathrm{m}$, радиус кривизны искривленной грани $R=32.3 \mu \mathrm{m}$, углы $\alpha=69^{\circ}, \beta=151^{\circ}$.

Искривленная грань за счет полного внутреннего отражения равномерно рассеивает параллельный луч света в широко расходящийся пучок. Причем рассеяние имеет место при значительном изменении угла наклона $\theta_{1}$ падающего солнечного излучения (рис. 4).

На рис. 5 приведены индикатрисы рассеяния падающего под углом к горизонту $\theta_{1}=40^{\circ}$ солнечного света для микропризматических структур обоих типов. На рис. 6 изображены развертки этих индикатрис рассеяния.

Следует особо отметить, что результаты здесь и далее во всех случаях, кроме оговоренных особо, приводятся для варианта, когда угол наклона солнца к горизонту $\theta_{1}$ расположен в вертикальной плоскости, нормальной к 


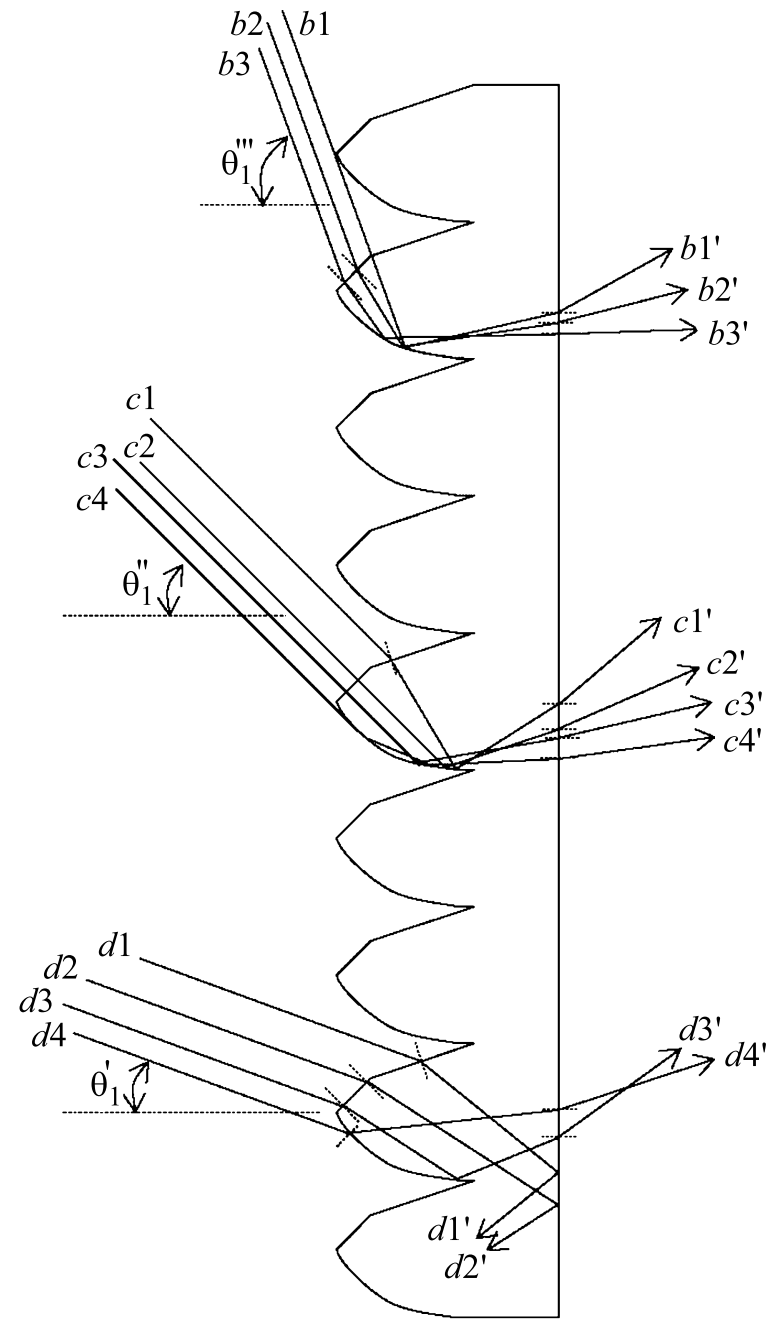

Рис. 4. Изменение характера прохождения через вертикально расположенную микропризматическую структуру типа 2 потоков параллельных солнечных лучей при последовательном увеличении угла падения $\theta_{1}\left(\theta_{1}^{\prime}<\theta_{1}^{\prime \prime}<\theta_{1}^{\prime \prime \prime}\right)[6]$.

вертикальной плоскости окна. Такое состояние соответствует значению азимутального угла $\varphi=90^{\circ}$. Указанные плоскости совпадают при $\varphi=0^{\circ}$.

Падающий солнечный свет состоит из параллельных лучей. Микроструктура типа 1 перенаправляет солнечный свет в виде узкого слабо расходящегося потока высокой интенсивности, образующего яркое пятно. При увеличении угла подъема солнца этот поток сдвигается вверх на потолок и яркое пятно перемещается в течение дня. Часть солнечного света также в виде узкого луча высокой интенсивности направляется вниз. Направленный вниз свет вызывает блескость.

Структура типа 2 рассеивает свет в виде широко расходящегося потока равномерной интенсивности. Основная часть света рассеивается вверх в диапазоне угла $\theta_{2}$ от 90 до $160^{\circ}$. Незначительная часть света в диапазоне $\theta_{2}=80-90^{\circ}$ перенаправляется вниз. Структура типа 2 обеспечивает равномерное естественное осве- щение помещения большой глубины при перемещении солнца в течение дня [6]. На распределение освещенности в помещении существенное влияние оказывает потолок, на который падает и от которого отражается перенаправленный свет. Он должен обладать высокой отражательной и рассеивающей способностью (белый матовый).

На рис. 7 изображено поперечное сечение микропризматической пленки, полученное с помощью сканирующего электронного микроскопа. Микроструктурная пленка изготавливается с использованием высокопроизводительной непрерывной технологии при перематывании с барабана на барабан (roll-to-roll - R2R) со скоростью $3 \mathrm{~m} / \mathrm{min}$. Вначале на пленку из полиэтилентерефталата (ПЭТ) наносится слой преполимера. Затем с помощью вращающейся матрицы выдавливается

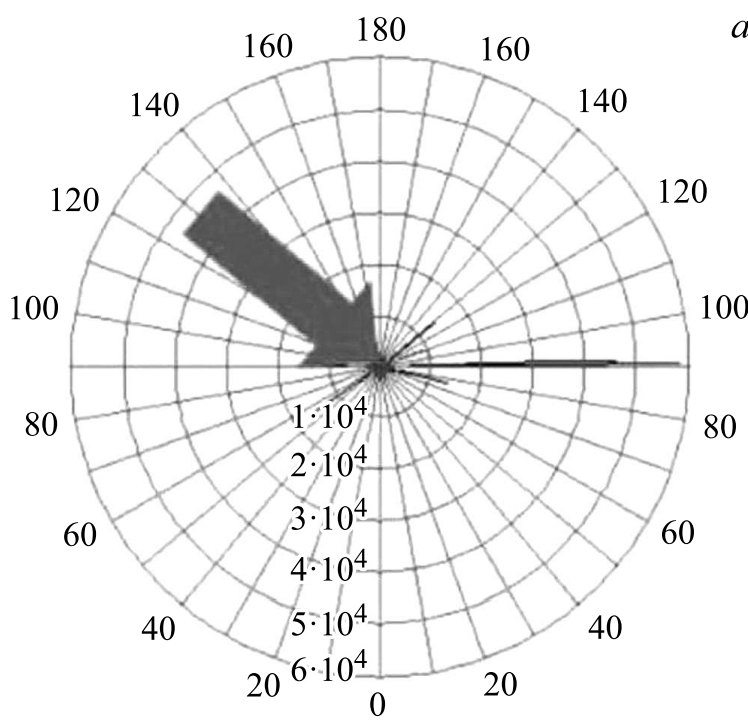

$a$

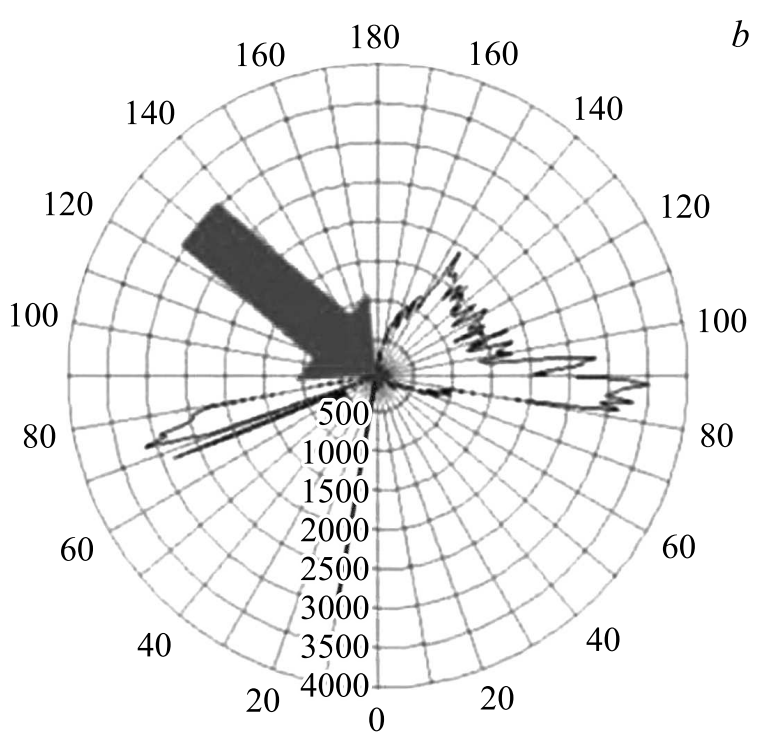

Рис. 5. Полярные диаграммы (индикатрисы) рассеяния падающего под углом $\theta_{1}=40^{\circ}$ к горизонту солнечного света вертикально расположенными изображенными на рис. 3 микропризматическими структурами типа $1(a)$ и типа $2(b)[6]$. 

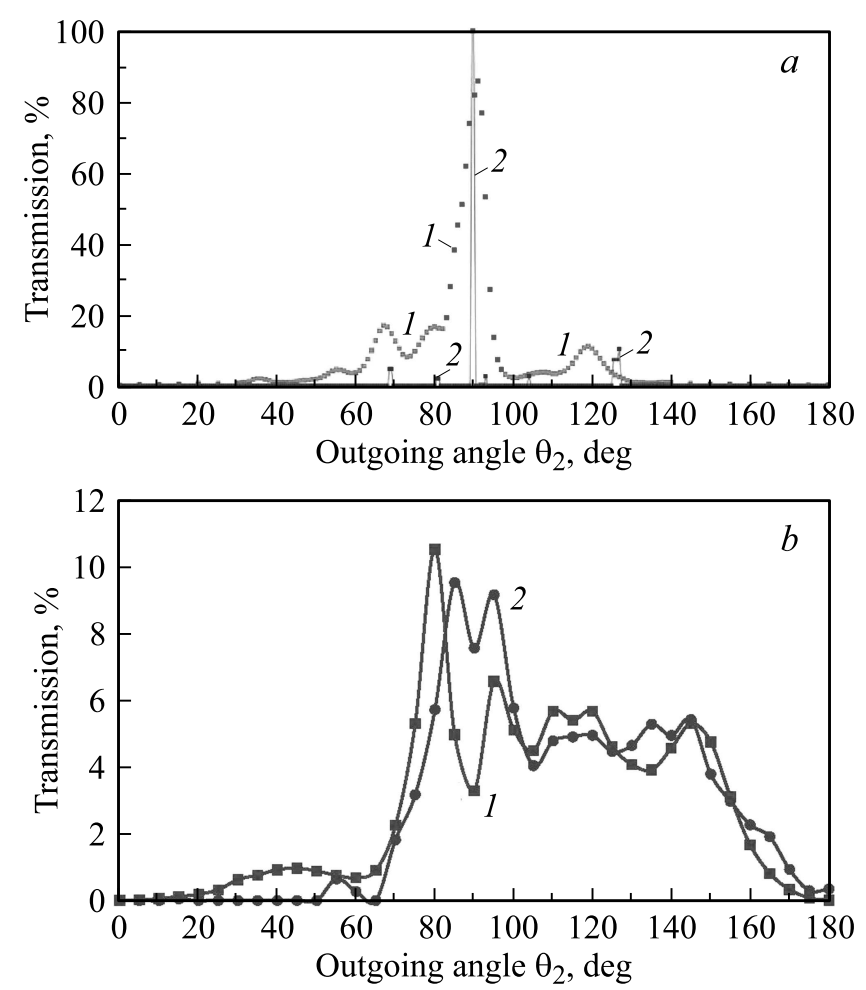

Рис. 6. Экспериментальные (1) и расчетные (2) результаты углового распределения интенсивности проходящего через изображенные на рис. 3 микропризматические структуры типа $1(a)$ и типа $2(b)$ солнечного света, падающего на них под углом $\theta_{1}=40^{\circ}$ к горизонту [4]. Угол выхода излучения $\theta_{2}=0^{\circ}$ соответствует направлению вертикально вниз, $\theta_{2}=180^{\circ}-$ вертикально вверх.

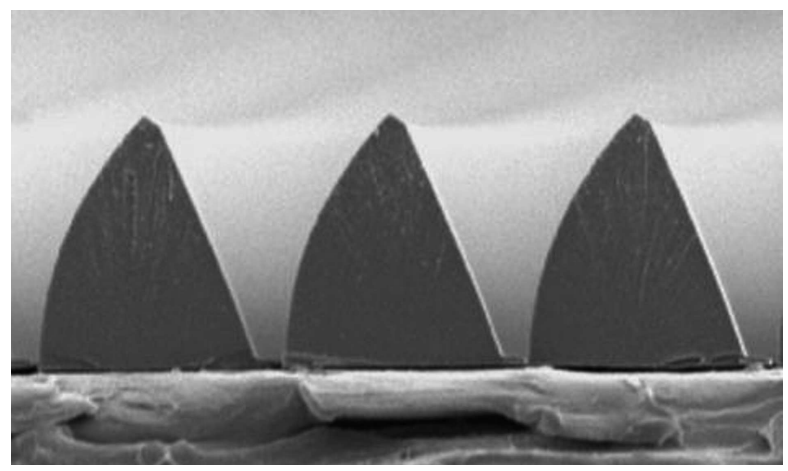

Рис. 7. Изображение поперечного сечения пленки с призматической микроструктурой типа 2 в сканирующем электронном микроскопе при увеличении в 1000 раз [4].

микропризматический профиль при одновременной фотополимеризации под воздействием ультрафиолетового излучения высокой плотности $120 \mathrm{~W} / \mathrm{cm}^{2}$. Рулон готовой микропризматической пленки изображен на рис. 8 . На ровную поверхность наносится адгезионный слой и защитная удаляемая пленка.

По технологии перематывания пленки с барабана на барабан изготовлена также сложная по строению пленка

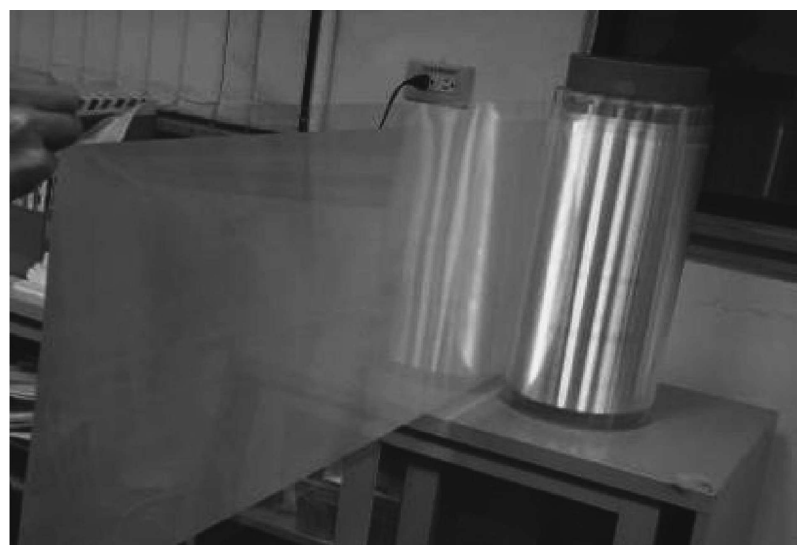

Рис. 8. Рулон готовой пленки с призматической микроструктурой [4].

с микропризматической перенаправляющей свет структурой с одной стороны и с наноструктурным просветляющим покрытием в виде бугорков высотой 127 и диаметром основания $330 \mathrm{~nm}$ и спектрально-селективным серебряным покрытием толщиной $15 \mathrm{~nm}$ с другой стороны [6].

Несколько позднее, с задержкой на 2-3 года, разработку микропризматической пленки $3 \mathrm{M}^{\mathrm{TM}}$ выполнили сотрудники американской компании 3М [7-9]. Результаты исследований освещенности в помещениях при использовании этой пленки в верхней части окон в натурных условиях приведены в работах [10-12]. Описание и характеристики микроструктуры пленки $3 \mathrm{M}^{\mathrm{TM}}$ приведены в [12], подробные результаты измерения ее оптических характеристик сообщаются в работе [11].

Микроструктура пленки $3 \mathrm{M}^{\mathrm{TM}}$ четырехгранная, близкая по форме к структуре типа 1 на рис. 3. Высота профиля микропризмы $H \sim 46 \mu \mathrm{m}$, шаг $P \sim 30 \mu \mathrm{m}$ [12].

Вследствие достаточного сходства геометрических характеристик микропризм $3 \mathrm{M}^{\mathrm{TM}}$ и типа 1 , оптические характеристики микроструктурной пленки $3 \mathrm{M}^{\mathrm{TM}}$ также достаточно близки к аналогичным характеристикам структуры типа 1 .

На рис. 9 приведены данные по рассеиванию света микроструктурной пленкой $3 \mathrm{M}^{\mathrm{TM}}$ при наклоне солнца к горизонту $\theta_{1}=40^{\circ}$. Аналогичные данные для структуры типа 1 изображены на рис. 6, a. Использована различная схема отсчета угла наклона перенаправляемого света. На рис. 6, $a$ изменению направления от вертикального вниз до вертикального вверх отвечает изменение угла $\theta_{2}$ слева-направо от 0 до $180^{\circ}$, на рис. 9 движению снизувверх отвечает изменение угла $\theta_{2}$ справа-налево от -70 до $+82.5^{\circ}$.

Микроструктура $3 \mathrm{M}^{\mathrm{TM}}$ перенаправляет солнечный свет в виде направленного вверх под углом $30^{\circ}$ к горизонту острого узкого луча высокой интенсивности, образующего яркое пятно. Для сравнения отметим, что структура типа 1 при таких условиях перенаправляет солнечный свет горизонтально. 


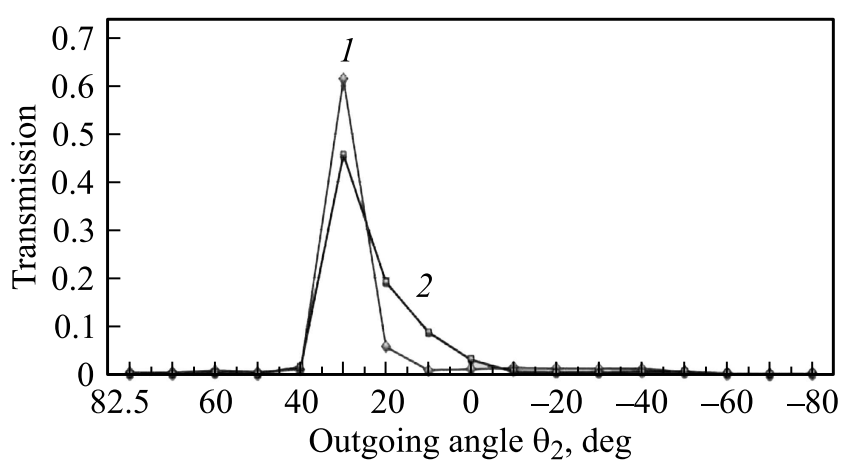

Рис. 9. Экспериментальные (1) и расчетные (2) результаты углового распределения интенсивности проходящего через наклеенную на вертикальное стекло толщиной $3 \mathrm{~mm}$ микропризматическую пленку $3 \mathrm{M}^{\mathrm{TM}}$ солнечного света, падающего на нее под углом $\theta_{1}=40^{\circ}$ к горизонту [11]. Угол выхода света $\theta_{2}=82.5^{\circ}$ соответствует направлению вверх на потолок, $\theta_{2}=-70^{\circ}-$ вниз на пол.

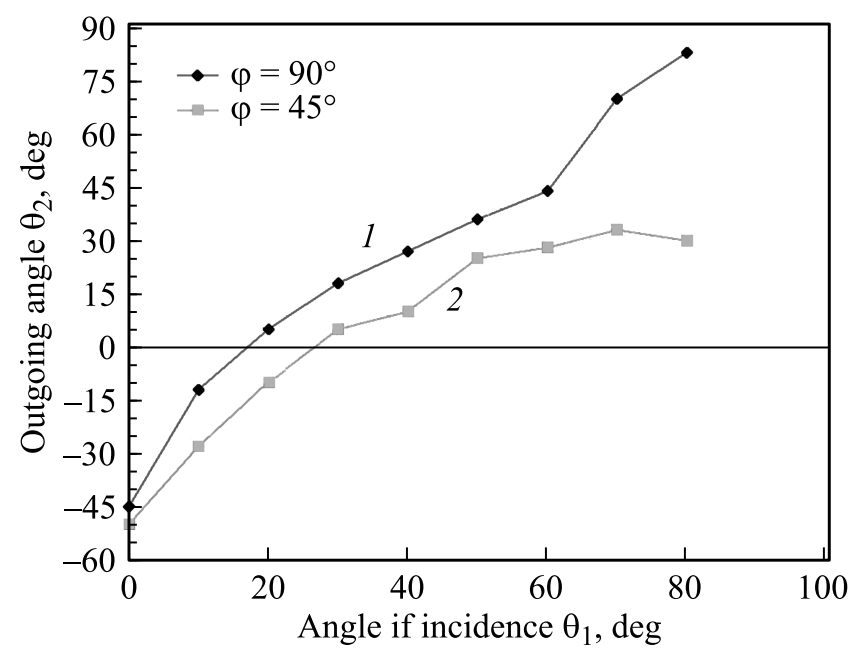

Рис. 10. Зависимость угла $\theta_{2}$ выхода из вертикально расположенной микропризматической пленки $3 \mathrm{M}^{\mathrm{TM}}$ основной части потока света от угла наклона к горизонту $\theta_{1}$ солнца. Угол наклона солнца к горизонту $\theta_{1}$ изменяется в вертикальной плоскости, нормальной к поверхности пленки $\varphi=90^{\circ}(1)$, и в вертикальной плоскости под азимутальным углом $\varphi=45^{\circ}$ к поверхности пленки (2) [11].

При углах подъема солнца $\theta_{2}>20^{\circ}$ основная часть выходящего из микроструктуры $3 \mathrm{M}^{\mathrm{TM}}$ света перенаправляется вверх (кривая 1 на рис. 10). На рис. 10 приведены также данные (кривая 2), характеризующие изменение перенаправления света при отклонении вертикальной плоскости солнечных лучей от вертикальной плоскости, нормальной к поверхности стекла. При уменьшении азимутального угла $\varphi$ от 90 до $45^{\circ}$ снижается угол $\theta_{2}$ наклона к горизонту основной части выходящего из пленки света.

Вследствие сходства структурных характеристик пленка $3 \mathrm{M}^{\mathrm{TM}}$ обладает тем же недостатком, что и микроструктура типа 1 - свет выходит в виде узконаправ-

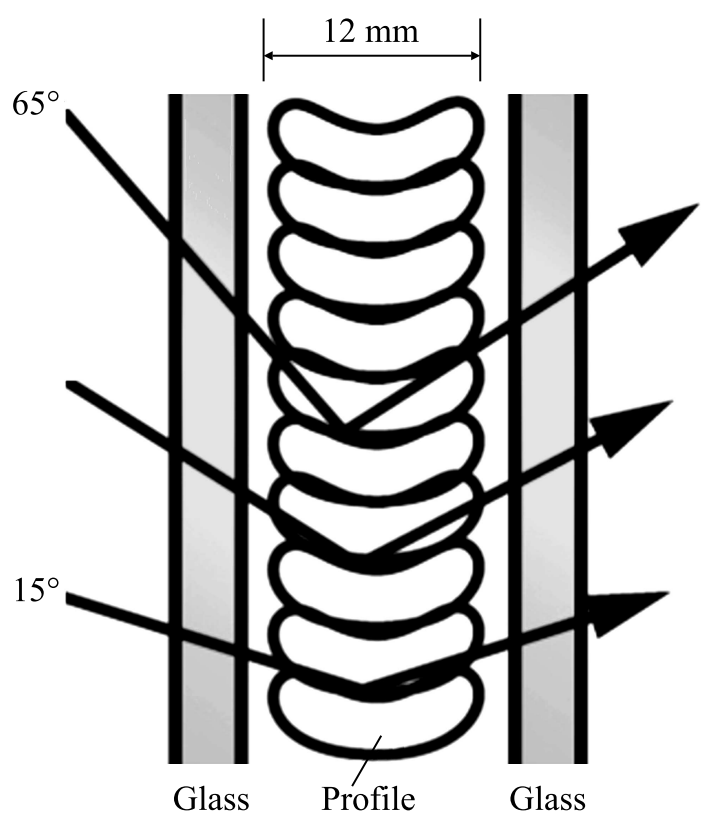

Рис. 11. Стеклопакет с блоком перенаправляющих солнечный свет элементов LUMITOP ${ }^{\circledR}[13]$.

ленного пучка высокой интенсивности. Кроме того, при использовании пленки $3 \mathrm{M}^{\mathrm{TM}}$ появляется слабый радужный ореол вследствие присущей призмам хроматической аберрации [10]. Поэтому для повышения равномерности распределения перенаправляемого света и устранения радужного ореола при использовании пленки $3 \mathrm{M}^{\mathrm{TM}}$ рекомендуется дополнительно использовать светорассеивающую пленку [8-12]. В однокамерном стеклопакете пленку $3 \mathrm{M}^{\mathrm{TM}}$ наклеивают на 2-ю поверхность (внутренняя поверхность наружного стекла), светорассеивающую пленку размещают на 3-й поверхности (внутренняя поверхность внутреннего стекла). При воздействии солнечного света стеклопакет с двумя пленками выглядит с внутренней стороны в виде светящейся покрытой инеем поверхности.

Стоимость пленки $3 \mathrm{M}^{\mathrm{TM}}$ составляет порядка $233 \mathrm{euro} / \mathrm{m}^{2}$.

\section{3. Панели с призматическими микроструктурами} на двух поверхностях. Перенаправляющее солнечный свет оптическое устройство LUMITOP ${ }^{\circledR}$ представляет собой совокупность вогнутых прозрачных профилей из ПММА, которые уложены в блок между стеклами (рис. 11). Профили размером $3.5 \times 12 \mathrm{~mm}$ изготовлены методом экструзии. Такие изделия выпускает компания Saint-Gobain Glass [13].

Профили элементов спроектированы для перенаправления падающего в диапазоне углов от 15 до $65^{\circ}$ солнечного света, что соответствует условиям центральной Европы. Падающий свет фокусируется первой поверхностью элемента, затем за счет полного внутреннего отражения от нижней поверхности направляется вверх на потолок и от него в глубину помещения. Задняя кромка 
каждого профиля выполнена волнистой для рассеяния света в горизонтальном направлении.

Для эффективного естественного освещения помещений в умеренном климате стеклопакеты с блоками элементов LUMITOP ${ }^{\circledR}$ должны размещаться в верхней части окна и иметь высоту не менее 0.1 высоты помещения. Это устройство непрозрачно для просмотра изнутри. Снаружи оно выглядит молочно-белым.

Максимальные размеры блоков из элементов LUMITOP $^{\circledR} \quad 600 \times 2600 \mathrm{~mm}$. Блоки шириной более $600 \mathrm{~mm}$ изготавливаются с вертикальной разделяющей планкой. Расстояние между стеклами $24 \mathrm{~mm}$. Дополнительная (к стоимости стеклопакета) стоимость перенаправляющих свет блоков оптических элементов LUMITOP ${ }^{\circledR}$ составляет около 200 euro/m².

Устройство LUMITOP ${ }^{\circledR}$ состоит из составных элементов и имеет значительную толщину и массу. Группа исследователей в Германии задалась целью создать устройство для перенаправления света с лучшими оптическими характеристиками в виде более легкой сплошной панели меньшей толщины. Кроме того, сплошная панель выполняет функцию дополнительного стекла в стеклопакете, что улучшает его теплотехнические свойства. Продолжительные поисковые разработки панели с оптическими микроструктурами с двух сторон [14-17] завершены и получили практическое воплощение в ходе четырехлетней 2016-2019 гг. государственной программы „TaLED“ (Energy- and cost efficient, façade integrated
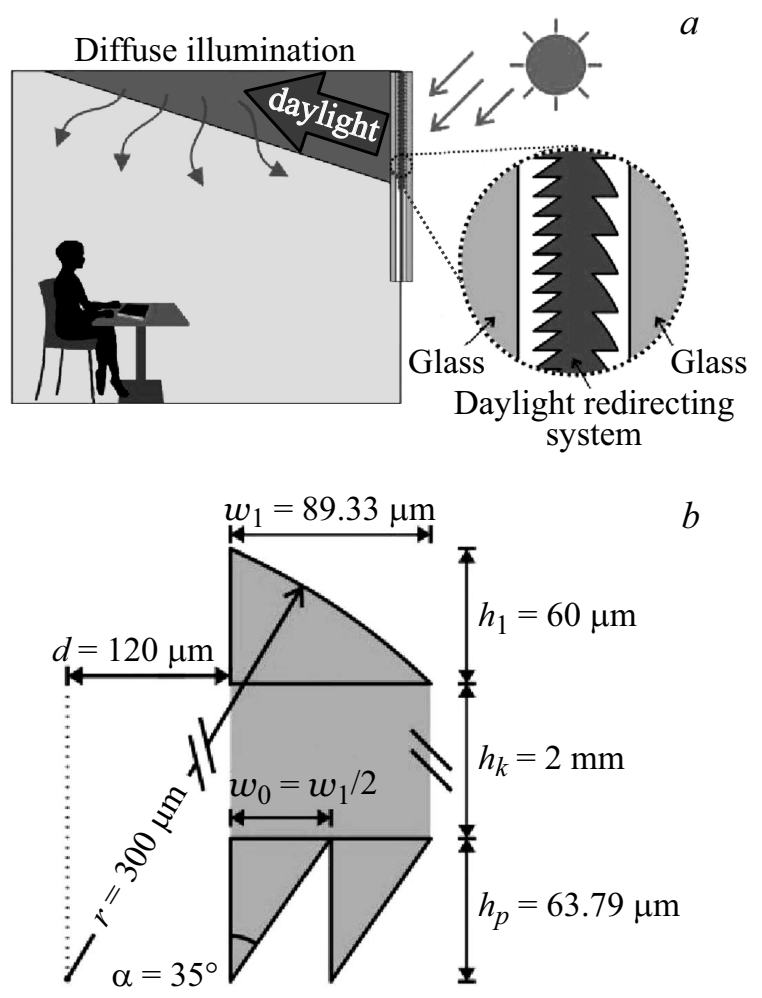

Рис. 12. Схема размещения $(a)$ и поперечное сечение панели с призматическими микроструктурами на двух сторонах $(b)$ [17].

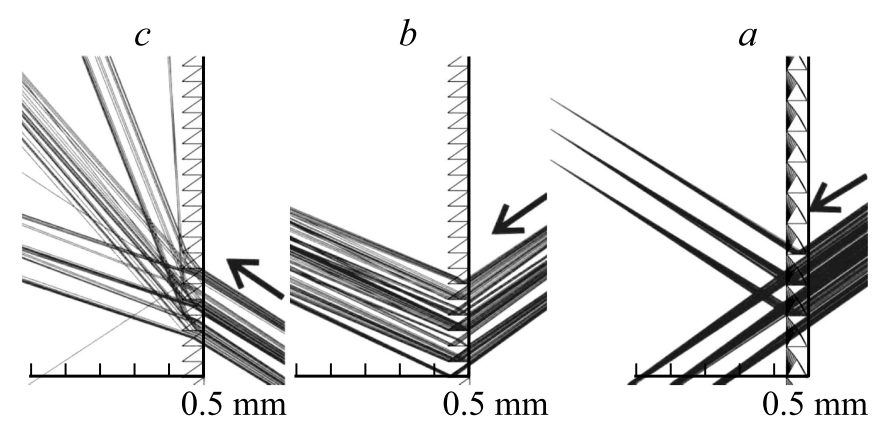

Рис. 13. Распределение лучей солнечного света, падающего справа под углом $\theta_{1}=35^{\circ}$ к горизонту, при прохождении через панель с призматическими микроструктурами на двух сторонах [17]. Стрелки показывают направление света.

Day- and LED lighting based on mico-optical components) при кооперации научных, производственных и архитектурных организаций [18].

На рис. 12 изображена схема размещения и поперечное сечение разработанной панели с призматическими микроструктурами на обеих сторонах. С внешней (солнечной) стороны панели расположена линзообразная микроструктура, с внутренней стороны - трехгранная. Толщина панели $2 \mathrm{~mm}$. Линзообразная структура имеет шаг $89.33 \mu \mathrm{m}$, высоту $60 \mu \mathrm{m}$, радиус закругления цилиндрической поверхности $300 \mu \mathrm{m}$. На внутренней стороне панели трехгранные микропризмы высотой $63.79 \mu \mathrm{m}$ имеют вдвое меньший шаг $44.67 \mu \mathrm{m}$.

На рис. 13 приведены результаты расчета хода лучей света, падающего справа под углом $\theta_{1}=35^{\circ}$ к горизонту. Линзообразная микроструктура на внешней поверхности разделяет падающий свет на два сфокусированных луча: один проходит вниз, второй после полного внутреннего отражения от горизонтальной плоской грани направлен вверх. Микроструктура на внутренней поверхности рассеивает и перенаправляет основную часть обоих потоков вверх. Толщина панели должна быть не меньше двух фокусных расстояний линзообразной структуры. Это позволяет избежать нежелательного эффекта резкого изменения направления выходящего света при малом изменении наклона падающего света, присущего призматическим структурам с плоскими гранями.

Оптические характеристики панели с призматическими микроструктурами на двух сторонах приведены на рис. 14. Схема выполнения измерений и отсчета углов показана на рис. 14, $a$. Угол выхода света из устройства $\theta_{2}=90^{\circ}$ соответствует направлению вертикально вверх, $\theta_{2}=-90^{\circ}-$ вниз.

Устройство разделяет падающий под углом $45^{\circ}$ солнечный свет на четыре расходящихся потока (рис. 14, $b$ ). Три из них, содержащие основную часть света, направлены вверх, четвертый, малой интенсивности, - вниз.

Вверх направлена основная часть света при изменении угла подъема солнца $\theta_{1}$ от 10 до 65 ${ }^{\circ}$ (рис. 15). Причем во всем этом диапазоне панель с двумя микро- 

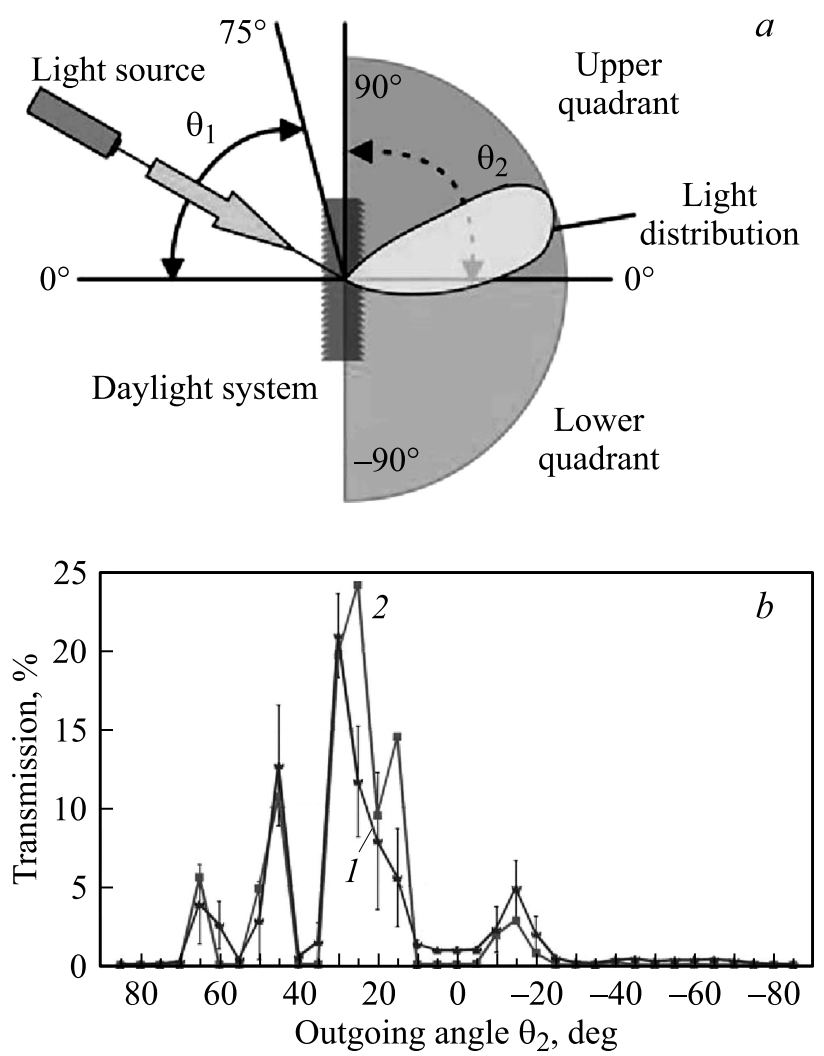

Рис. 14. Оптические свойства панели с призматическими микроструктурами на двух сторонах [16]. Схема измерений с использованием гониофотометра $(a)$. Экспериментальные $(1)$ и расчетные (2) результаты по угловому распределению интенсивности солнечного света на выходе из панели при падении его под углом $\theta_{1}=45^{\circ}$ к горизонту $(b)$.

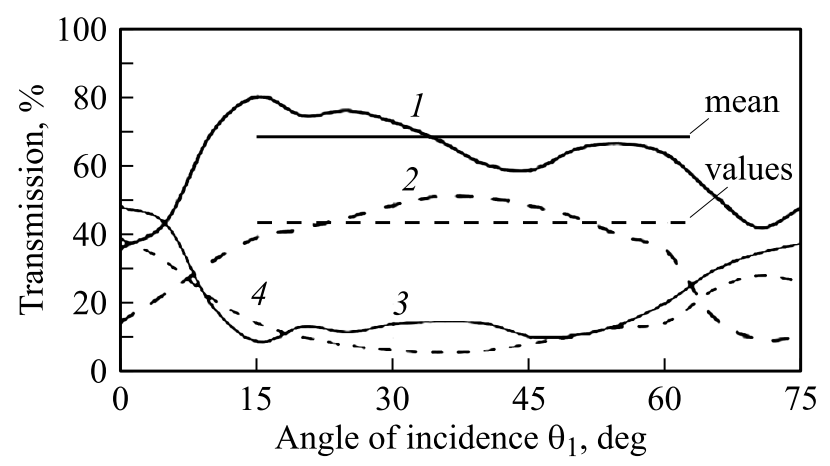

Рис. 15. Доли направленного вверх $(1,2)$ и вниз $(3,4)$ солнечного света после изготовленной из полидиметилсилоксана (ПДМС) панели с призматическими микроструктурами на двух сторонах $(1,3)$ и после блока элементов LUMITOP $^{\circledR}(2,4)[16]$.

призматическими поверхностями перенаправляет вверх в среднем примерно на $25 \%$ больше света, чем устройство LUMITOP ${ }^{\circledR}$.

При наличии индикатрис рассеяния света различными призматическими микроструктурами имеется возможность сравнить характер рассеяния ими падающего под

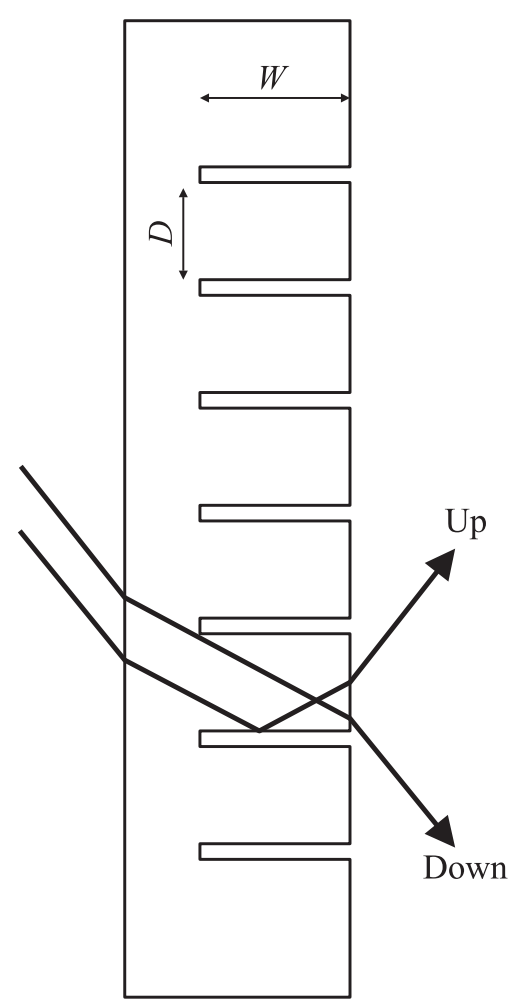

Рис. 16. Расщепление солнечного света в надрезанной лазером панели [19].

одинаковым углом $40^{\circ}$ солнечного света. Такие данные приведены для микропризматической четырехгранной структуры с одной искривленной гранью (тип 2) на рис. $6, b$, для четырехгранной микропризматической структуры с плоскими гранями на рис. $6, a$ (тип 1) и рис. $9\left(3 \mathrm{M}^{\mathrm{TM}}\right)$, для панели с призматическими микроструктурами на двух сторонах - на рис. $14, b$. Лучшими свойствами обладают микроструктуры с одной искривленной гранью - из них выходит направленный вверх поток равномерной интенсивности с большим углом раствора (рис. $6, b$ и рис. $14, b$ ).

\section{2. Панели и пленки с микрозеркалами}

2.1. Надрезанные лазером панели. Надрезанные лазером панели изготавливают нарезкой лазерным лучом щелей-надрезов в прозрачной пластине из ПММА толщиной около $5 \mathrm{~mm}$ (рис. 16). Под воздействием лазерного луча полимер плавится и испаряется с образованием полированных поверхностей. Каждая поверхность становится маленьким зеркалом, которое отражает проходящий через панель свет за счет полного внутреннего отражения. Канавки можно изготовить двумя способами [19]:

— прорезкой на заданную глубину;

- сквозной прорезкой пластины с последующим ее ламинированием другой тонкой пластиной из этого же материала. 


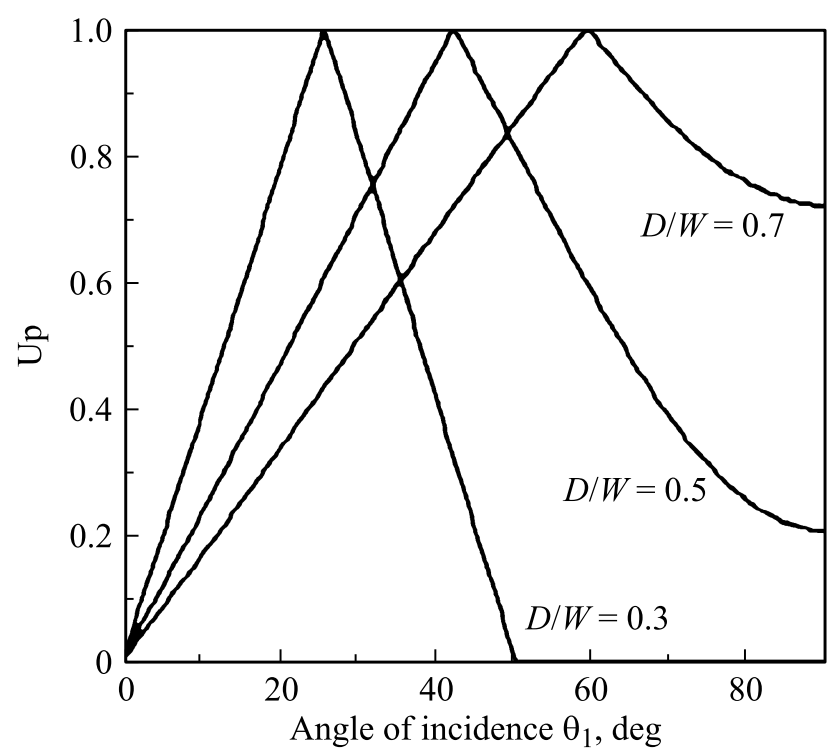

Рис. 17. Зависимость величины перенаправляемой вверх доли света Up от угла подъема солнца для панелей с различным соотношением $D / W[19]$.

В обоих вариантах необходимо оставлять сплошные перемычки 20-30 mm для обеспечения структурной целостности панели. Затем надрезанная лазером панель ламинируется между двумя тонкими стеклами толщиной 1.0-1.5 mm. Достоинством такой панели является ее высокая прозрачность - при просмотре через нее по нормали к поверхности изображение практически не искажается.

Поток входящего в пластину света разделяется на две части: одна часть (Down) проходит без изменения направления вниз, вторая (Up) испытывает полное внутреннее отражение от поверхности щелей и выходит вверх под таким же углом к горизонту.

Соотношение между долями проходящего через пластину света определяется двумя параметрами:

- углом наклона $\theta_{1}$ солнечного света к горизонту;

- соотношением $D / W$ между глубиной канавок $W$ и расстоянием $D$ между ними.

На рис. 17 показано изменение доли перенаправленного вверх светового потока в зависимости от угла его падения для трех геометрических характеристик. Во всех вариантах с увеличением угла падения доля перенаправленного вверх светового потока вначале увеличивается до предельного значения. В этом случае весь проходящий через пластину свет перенаправляется вверх. Величина соответствующего угла $\theta_{1}$ зависит от геометрических параметров: чем меньше расстояние между канавками при их одинаковой глубине, тем при меньшем значении угла $\theta_{1}$ это происходит. Изменением геометрического параметра $D / W$ для заданных условий (угол $\theta_{1}$ ) можно подобрать оптимальный вариант для перенаправления света на потолок.
Следует особенно подчеркнуть, что важнейшей геометрической характеристикой такого изделия служат не абсолютные размеры $D$ и $W$, а именно соотношение между ними $D / W$.

Ламинированные стеклами надрезанные лазером акриловые панели толщиной от 2 до $20 \mathrm{~mm}$ стоимостью порядка $100 \$ / \mathrm{m}^{2}$ выпускает австралийская компания SOLARTRAN [20].

2.2. Пластины с микрощелями SerraGlaze ${ }^{\circledR}$. Надрезанные лазером панели в уменьшенном размере нашли воплощение в виде микрощелевой пластины SerraGlaze ${ }^{\circledR}$ производства компании SerraLux Inc [21]. „Serra“ Stacked Elemental Refractor/Reflector Array. Конструкция изделия защищена основным патентом [22]. Подробное описание технологии изготовления и основные характеристики пластины приведены в работе [23].

Структура пластины изображена на рис. 18. В исходной нагретой пластине из ПММА толщиной $0.5 \mathrm{~mm}$ и размерами $300 \times 300 \mathrm{~mm}$ методом микрорепликации с высокой точностью выдавливают канавки-выступы формы, близкой к прямоугольной. Высота выступов $\sim 0.5 \mathrm{~mm}$, толщина $\sim 0.3 \mathrm{~mm}$. Вершины выступов смазывают ультратонким (нескольк $\mu \mathrm{m})$ слоем фотополимеризуемого клейкого состава и две изготовленные такие образом пластины вставляют друг в друга. При этом вершины выступов плотно прилегают, а между боковыми поверхностями выступов образуются микрощели треугольной формы средней толщиной $\sim 10 \mu \mathrm{m}$. В итоге после ламинирования и фотополимеризации клея получается сплошная монолитная пластина толщиной $\sim 1 \mathrm{~mm}$ с многочисленными внутренними микрощелями. Изготовленные квадратные пластины раскладывают в мозаику, с обеих сторон накрывают сначала липкой пленкой, а затем стеклами, и ламинируют. Готовое изделие SerraGlaze ${ }^{\circledR}$ представляет собой многослойное композитное стекло с установленной в центре ПММА пластиной с многочисленными горизонтальными микрощелями.

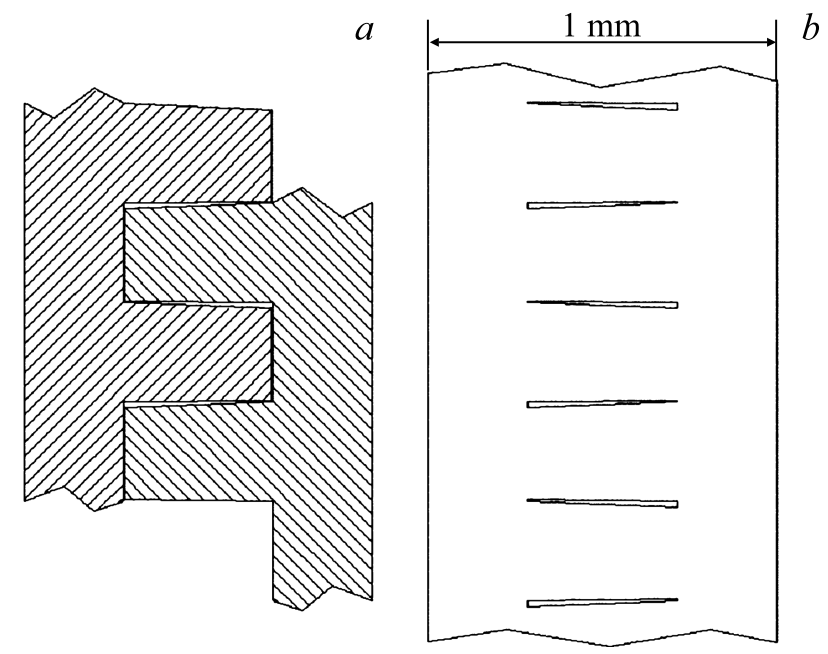

Рис. 18. Заготовки $(a)$ и готовое изделие $(b)$ SerraGlaze $^{\circledR}[23]$. 


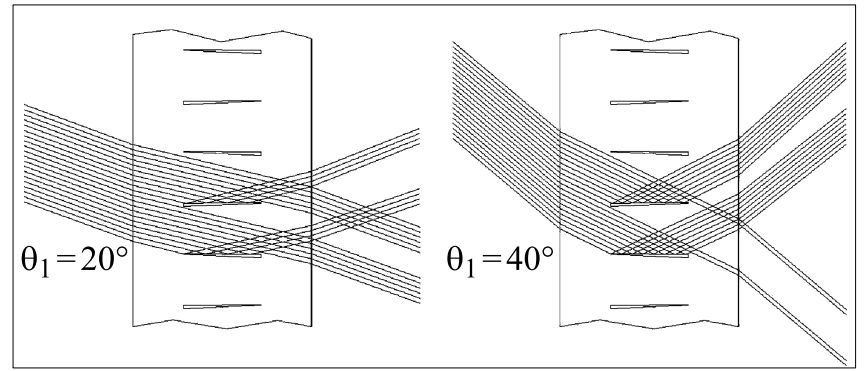

Рис. 19. Расщепление падающих с различными углами наклона солнечных лучей в пластине SerraGlaze ${ }^{\circledR}$ [23].

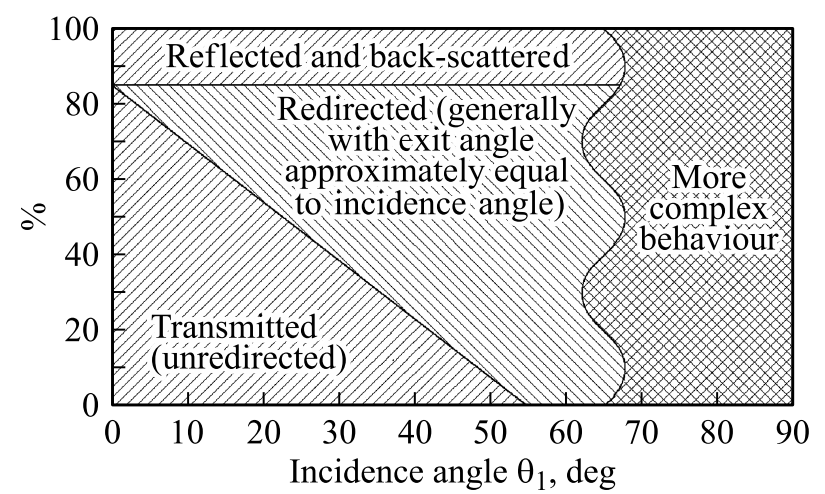

Рис. 20. Изменение соотношения между долями направленного, перенаправленного и отраженного обратно солнечного света при прохождении его через пластину SerraGlaze ${ }^{\circledR}$ в зависимости от угла падения [23].

При падении луча света на поверхность горизонтальной микрощели он отражается от нее в результате полного внутреннего отражения. На рис. 19 показан ход и расщепление световых лучей внутри такой пластины. Часть светового потока не меняет своего направления, часть симметрично отражается вверх. При увеличении угла падения возрастает доля перенаправленного вверх света.

Более полное представление о количественном соотношении между потоками проходящего через пластину света можно получить из приведенных на рис. 20 данных. Падающий горизонтально свет практически полностью (85\%) проходит сквозь пластину. Это свидетельствует о том, что при горизонтальном просмотре через пластину изображение практически не искажается. С увеличением угла $\theta_{1}$ возрастает доля перенаправленного вверх света за счет сокращения доли проходящего без изменения направления. Наклон прямой линии, определяющей соотношение между долями перенаправленного и не изменяющего направление света, зависит от соотношения между длиной щелей и расстояния между ними $(D / W \sim 0.6$ для данных на рис. 20$)$.

Недостатки надрезанных лазером панелей и пластин с микрощелями SerraGlaze ${ }^{\circledR}$ - они перенаправляют свет вверх в виде параллельного потока, создающего яркое пятно на потолке (блескость). Кроме того, узок диапазон углов $\theta_{1}$ наклона солнца, в котором свет перенаправляется вверх (узкий острый треугольный пик) и мала доля этого света (рис. 17, 20). Эти недостатки отчетливо проявляются при сравнении результатов для этих панелей (рис. 17, 20) и результатов на рис. 14 для устройств LUMITOP ${ }^{\circledR}$ и панелей с призматическими микроструктурами на двух сторонах.

2.3. Пленки с внедренными микрозеркалами. Дальнейшее развитие в направлении миниатюризации надрезанные лазером панели получили в виде полимерной пленки с внедренными микрозеркалами, предложенной группой швейцарских исследователей [24]. Снижение толщины до размеров меньше $1 \mathrm{~mm}$ и гибкость позволяют наклеивать пленку на стекло, тем самым значительно упрощая конструкцию и изготовление стеклопакета.

Полимерная пленка с внедренными микрозеркалами изображена на рис. 21, $a$. В полимерную пленку 1 внедрены параболические микрозеркала 2, в фокусе которых на внешней поверхности пленки расположены плоские микрозеркала 3. Примерные размеры изделия: толщина пленки $\sim 0.5 \mathrm{~mm}$, длина параболического микрозеркала $100-300 \mu \mathrm{m}$, расстояние между микрозеркалами равно примерно половине их длины, высота вертикальных микрозеркал 20-40 $\mu \mathrm{m}$.

Плоские зеркала (в надрезанных лазером панелях и в изделиях SerraGlaze $\left.{ }^{\circledR}\right)$ направляют отраженное вверх солнечное излучение в виде параллельного потока, который создает яркое пятно с большим градиентом освещенности и блескостью. Для устранения этого дефекта и предложены параболические микрозеркала (рис. $21, a)$. Направленный зимой под углом $25^{\circ}$ к горизонту параллельный поток солнечного света падает на параболическую зеркальную поверхность и отражается под различными углами и рассеивается. В результате из пленки выходит вверх расходящийся поток рассеянного света, который равномерно освещает потолок и дальнюю стену помещения.

Летом при высоком положении солнца отраженный параболическим микрозеркалом 2 свет фокусируется на поверхности вертикального микрозеркала 3 и отражается обратно. Этим устраняется перегрев помещения. Комбинация двух микрозеркал обеспечивает равномерное перенаправление рассеянного солнечного света и почти нулевое пропускание при выбранных углах подъема солнца около $60^{\circ}$, тем самым обеспечивая естественное освещение и сезонный контроль поступления теплоты.

Оптические характеристики пленки с внедренными микрозеркалами приведены на рис. $21, b$. Незначительное снижение светопропускания при углах подъема солнца в диапазоне $0<\theta_{1}<30^{\circ}$ вызвано отражением от вертикальных микрозеркал. В то же время малые поперечные размеры микрозеркал делают их невидимыми для невооруженного глаза. Поэтому эти пленки при просмотре сквозь них выглядят прозрачными и равномерно затененными по сравнению с бесцветным стеклом. При увеличении подъема солнца, начиная примерно с $\theta_{1}=10^{\circ}$, линейно возрастает доля направленного вверх 

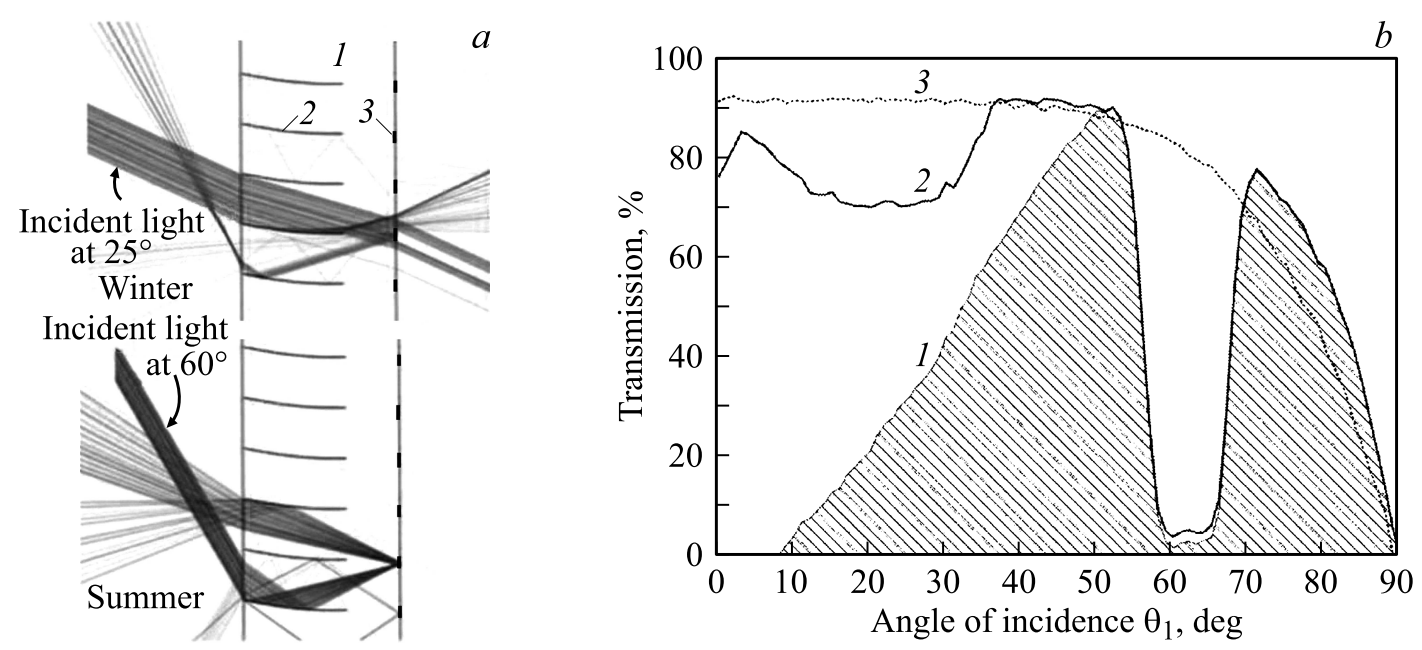

Рис. 21. Оптические свойства пленки с внедренными микрозеркалами [24]. (а) Структура полимерной пленки и расчетные результаты направления лучей солнечного света зимой и летом: 1 - полимерная пленка; 2 - параболическое микрозеркало; 3 плоское микрозеркало. (b) Светопропускание пленки при различных углах $\theta_{1}$ солнца над горизонтом: 1 - доля направленного вверх рассеянного света; 2 - полное светопропускание пленки; 3 - светопропускание бесцветного стекла толщиной 3 тm.

рассеянного света за счет снижения доли направленного вниз параллельно потока. При $\theta_{1}>50^{\circ}$ весь свет рассеивается вверх. Провал светопропускания в диапазоне $55<\theta_{1}<70^{\circ}$ обусловлен отражением от вертикальных микрозеркал. При отсутствии этих микрозеркал провал светопропускания также отсутствует.

Следует отметить, что оптические характеристики на рис. $21, b$ для пленки с внедренными микрозеркалами аналогичны оптическим свойствам надрезанных лазером панелей (рис. 17) и изделий SerraGlaze ${ }^{\circledR}$ (рис. 20). Но имеется качественное отличие: в первом случае вверх направляется рассеянный свет, в двух других вверх отражается направленный поток света.

Выполненные расчеты показали, что естественное освещение в солнечную погоду значительно улучшается в помещениях, в которых установлены однокамерные стеклопакеты с наклеенными на верхней части стекла (одной или двух третьих частей) пленками с внедренными микрозеркалами [25]. В этих помещениях, по сравнению с помещениями с такими же стеклопакетами без пленок, улучшается равномерность освещения вдоль помещения, повышается освещенность в глубине, снижается вероятность появления блескости.

Пленки с внедренными микрозеркалами обладают хорошими оптическими свойствами. Проблема заключается в их изготовлении. Для этого требуется выполнить последовательно ряд операций: формование полимерной микропризматической пленки, одна из граней которой имеет параболический профиль; напыление металлического зеркального покрытия на грань с параболическим профилем; заполнение микропризматической структуры таким же полимерным материалом с формированием гладкой поверхности на другой стороне; напыление внешнего металлического зеркального покрытия [24]. До последнего времени технологические сложности преодолеть не удалось. Основные проблемы возникают при изготовлении металлической матрицы для формования пленки с микроструктурными параболическими профилями. В ходе достаточно продолжительных разработок получены только образцы пленки малых размеров (не более $25 \times 45 \mathrm{~mm}$ ), причем без внешних зеркал $[24,26,27]$. Одна из причин - использование технологии, применимой для изготовления плоских изделий. Ранее было отмечено, что технология перематывания пленки с барабана на барабан (roll-to-roll - R2R) позволяет изготовить сложную по строению пленку с микропризматической перенаправляющей свет структурой с одной стороны и с наноструктурным просветляющим покрытием в виде бугорков высотой 127 и диаметром основания $330 \mathrm{~nm}$ и спектрально-селективным серебряным покрытием толщиной $15 \mathrm{~nm}$ с другой стороны [6].

\section{3. Переключаемые микрозеркала и микрожалюзи}

Оптические МикроЭлектроМеханические Системы (МЭМС) - микроустройства, содержащие подвижную часть, положение которой управляется электростатическими силами между двумя электродами в этих элементах. Оптические МЭМС изготавливают по технологиям микроэлектроники. Наиболее широкое распространение получили микрозеркала - электрически переключаемые миниатюрные зеркала размерами в диапазоне $10-1000 \mu \mathrm{m}$.

Первые цифровые микрозеркальные устройства были разработаны в конце 80-х годов для модулирования света в видеопроекторах и устройствах оптоэлектроники [28]. Такие устройства изготавливают в виде массива микрозеркал, которые электростатически отклоняются на 
Структурные и оптические свойства массивов микрожалюзи и микрозеркал

\begin{tabular}{c|c|c|c|c|c|c}
\hline Электроизолятор & $\begin{array}{c}\text { Подвижный } \\
\text { электрод }\end{array}$ & $\begin{array}{c}\text { Размеры } \\
\text { микростворки, } \mu \mathrm{m}\end{array}$ & $\begin{array}{c}\text { Активная площадь, } \\
\mathrm{cm}^{2}\end{array}$ & $\begin{array}{c}\tau^{+} / \tau^{-}, \\
\%\end{array}$ & $\begin{array}{c}\text { Напряжение } \\
\text { активации, } \mathrm{V}\end{array}$ & Литература \\
\hline- & - & $458 \times 2500$ & - & - & 80 & {$[30]$} \\
\hline $\mathrm{SiO}_{2}$ & $\mathrm{SiN}_{x} / \mathrm{SiO}_{2} / \mathrm{Al}^{\prime} / \mathrm{SiO}_{2} / \mathrm{SiN}_{x}$ & $150 \times 400$ & 100 & $75 / 2$ & $40-80$ & {$[35]$} \\
\hline $\begin{array}{c}\mathrm{SiO}_{2}, \\
\mathrm{SiN}_{x}, \mathrm{Al}_{2} \mathrm{O}_{3}\end{array}$ & $\mathrm{Cr}$ и другие, $100 \mathrm{~nm}$ & $\begin{array}{c}50 \times 150 ; \\
100 \times 150\end{array}$ & 20 & $60 / 0.1$ & $15-25$ & {$[34]$} \\
\hline $\begin{array}{c}\mathrm{SiO}_{2}, \\
200 \mathrm{~nm}\end{array}$ & $\begin{array}{c}\mathrm{SiO}_{2}, 200 \mathrm{~nm} / \mathrm{Al}, \\
100 \mathrm{~nm}\end{array}$ & $200 \times 30$ & 0.25 & $53 / 36$ & 55 & {$[33]$}
\end{tabular}

Примечание: $\tau^{+} / \tau^{-}$- отношение светопропускания в открытом $\tau^{+}-$и закрытом $\tau^{-}-$состояниях.

угол 10-12 и „выключено“. Эти устройства нашли применение в мультимедийных проекторах, оптических переключателях, астрономических телескопах.

Цифровые микрозеркальные устройства производства компании Texas Instruments содержат более 2 млн. $(2048 \times 1080)$ микрозеркал размером порядка $10 \times 10 \mu \mathrm{m}$. Для многоцелевого спектроскопа изготовлены микрозеркальные массивы, содержащие $2048 \quad(32 \times 64) \quad$ электростатически управляемых микрозеркал [29]. Каждое микрозеркало имеет размер $200 \times 100 \times 10 \mu \mathrm{m}$ и отклоняется на угол $25^{\circ}$ под действием напряжения $130 \mathrm{~V}$.

Позднее, в начале 2000-х годов, оптические МЭМС предложили использовать для управления световым потоком через стекла - в электрически переключаемых (динамических) стеклах. Это было сделано группами исследователей в нескольких странах [30-33]. Часть исследователей ограничилась однократной публикацией результатов. Продолжают разработки группы в Канаде [32,34] и в университете г. Кассель в Германии [31,35-38]. Подробные результаты опубликованы в виде отчета [35], статей [36,37] и диссертации [38].

Предложено два варианта оптических МЭМС - микрожалюзи [30,32,33] и микрозеркала [31]. На рис. 22 приведены изображения этих устройств. В состоянии „открыто“ микрожалюзи закручены, плоские микрозеркала отогнуты под углом, близким к прямому. При подключении напряжения на электроды под электростатическим воздействием те и другие выпрямляются, прилегают к стеклу и закрывают микроотверстия - ,закрыто“. Миниатюризация оптических элементов позволяет обеспечить их невидимость невооруженным глазом и значительно увеличить срок их эксплуатации.

Технология изготовления микрожалюзи включает пять операций нанесения тонкослойных покрытий и две операции их структурирования методом фотолитографии (рис. 23). Верхний электрод микрожалюзи обычно выполняется двухслойным для создания внутренних напряжений, под действием которых микрожалюзи закручиваются после удаления жертвенного слоя. При подключении напряжения между электродами микрожа- люзи под электростатическим воздействием раскручиваются и закрывают микроотверстие, а микрозеркала разгибаются и прилегают к стеклу.

Основные характеристики оптических МЭМС приведены в таблице.

Изготовить микрозеркало значительно сложнее, чем микрожалюзи, - необходимо обеспечить не закрученную, а плоскую отклоняемую поверхность. Но вследствие плоской формы микрозеркала и обладают рядом существенных преимуществ.

Структура первых микрозеркал и их взаимодействие с потоком солнечного света в закрытом и открытом состояниях изображена на рис. 24,25 . Здесь зеркало выполнено пятислойным. Свет отражается от зеркального алюминиевого слоя. Совершенствование технологии изготовления и структуры плоских отклоняемых микрозеркал продолжается более 15 лет [31,35-38].

Для изготовления изображенного на рис. 24, 25 микрозеркала необходимо выполнить восемь операций нанесения тонкослойных покрытий и три операции их структурирования методом фотолитографии. Микрозеркало состоит из нескольких слоев различного материала. Многослойная структура необходима:

- для создания предварительно напряженного состояния на шарнирном участке микрозеркала - после удаления жертвенного слоя шарнирный участок под действием внутренних напряжений изгибается;

- для обеспечения плоской формы основной части зеркала.

Каждое микрозеркало якорной частью прикреплено к стеклу. Якорная часть является электропроводником, с помощью которого алюминиевый зеркальный слой подключается к источнику электропитания.

В свободном состоянии микрозеркало отогнуто от стекла. Шарнирная часть делает микрозеркало подвижным. Когда между электропроводящим светопрозрачным слоем и металлическим зеркальным слоем создается электрическое поле в результате подключения напряжения, между слоями возникают электростатические силы притяжения, под действием которых микрозеркало притягивается к поверхности стекла. При отключении электрического поля шарнирная часть под действием 

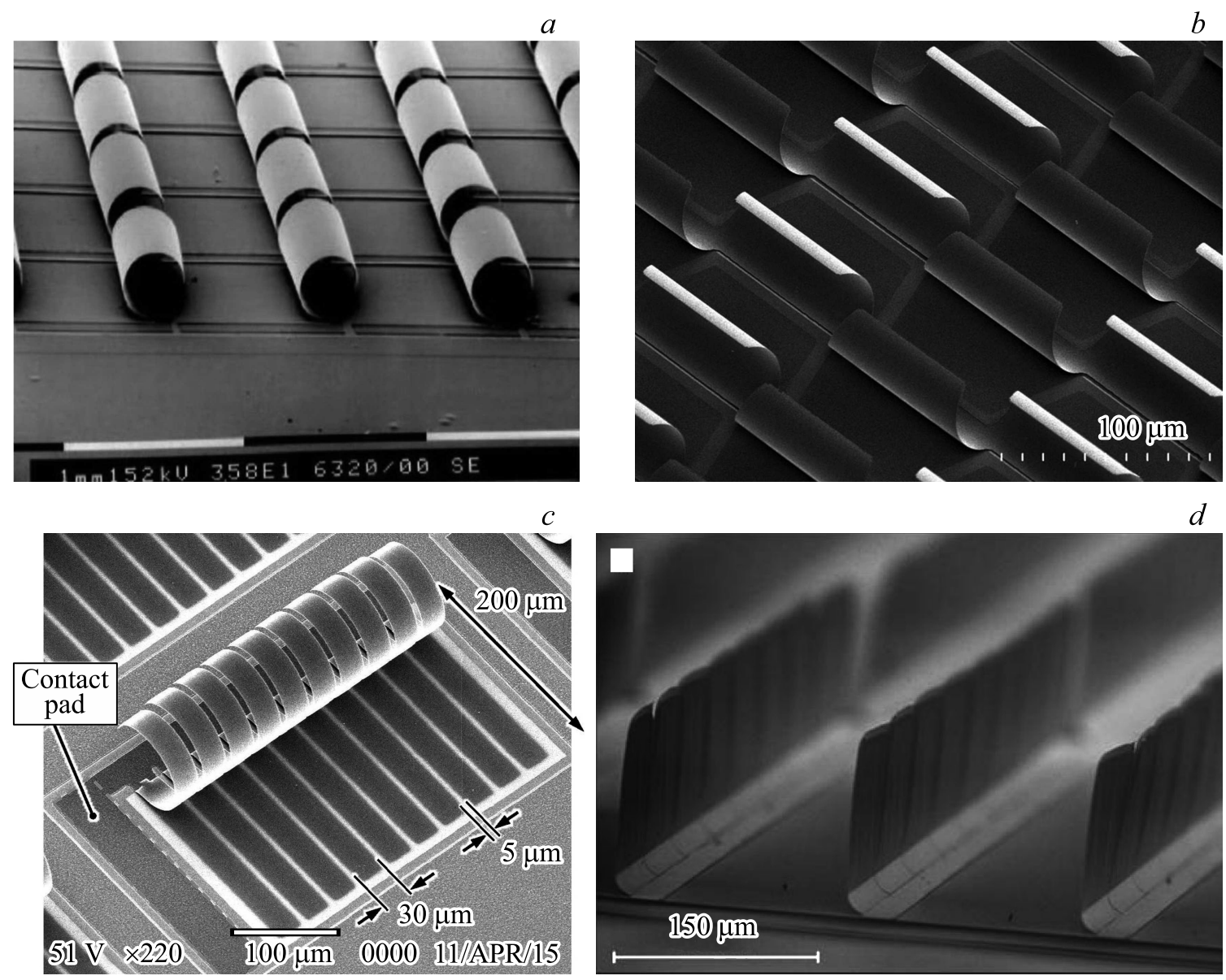

Рис. 22. Изображения в сканирующем электронном микроскопе оптических микроэлектромеханических систем в открытом состоянии: $a$ - микрожалюзи [30], $b$ - микрожалюзи [34], $c$ - микрожалюзи [33], $d$ - микрозеркала [38].
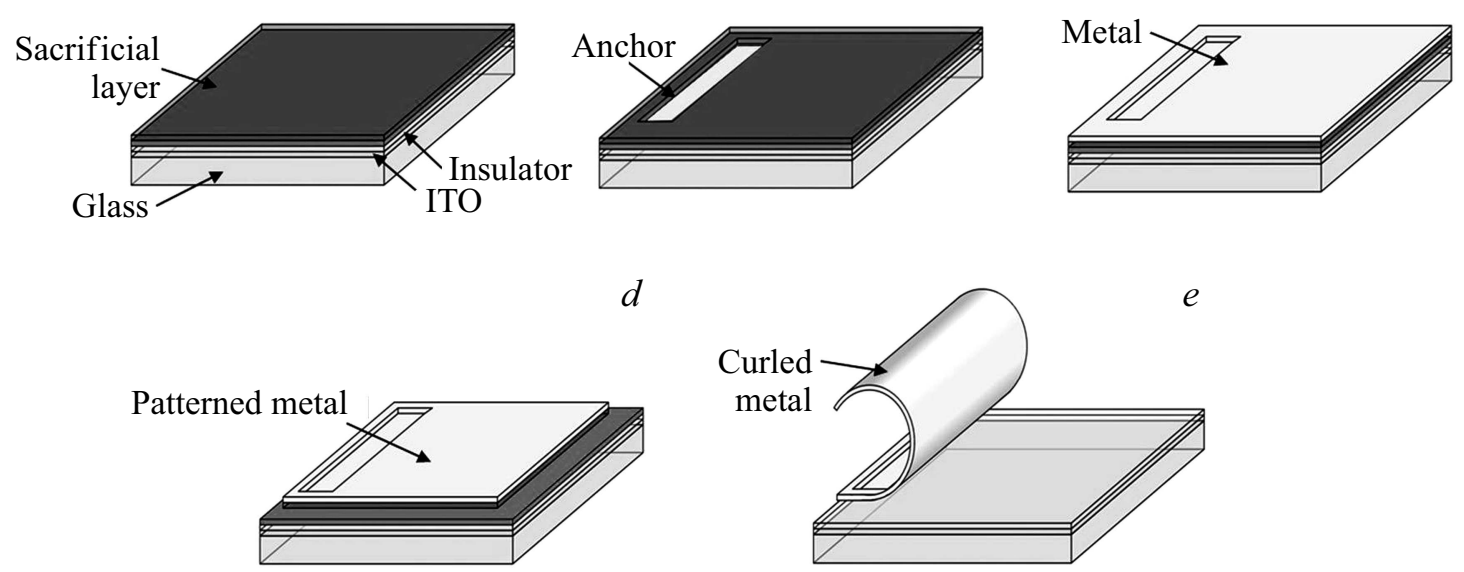

Рис. 23. Типичная схема изготовления микрожалюзи [34]. (а) Стеклянная подложка с нанесенными последовательно слоями прозрачного электропроводящего оксида ITO - нижний электрод (ITO - Indium Tin Охіde - легированный оловом оксид индия $\left.\mathrm{In}_{2} \mathrm{O}_{3}: \mathrm{Sn}\right)$, изолятора $\left(\mathrm{SiO}_{2}\right)$ и жертвенного слоя; $(b)$ структурирование жертвенного слоя фотолитографией для освобождения места крепления якоря; $(c)$ напыление верхнего двухслойного электрода; $(d)$ структурирование верхнего электрода фотолитографией; $(e)$ высвобождение микрожалюзи путем удаления жертвенного слоя. 


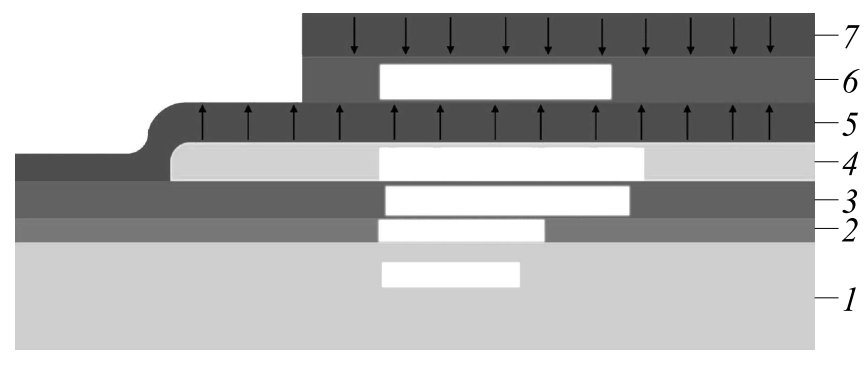

Рис. 24. Вариант структуры микрозеркала [35]: 1 - стекло; 2 - прозрачный электропроводящий слой; 3 - электроизолирующий слой $\left(\mathrm{SiO}_{2}\right) ; 4-$ жертвенный слой; 5 двухслойный опорный слой (основа микрозеркала), состоящий последовательно из слоев нитрида кремния $\mathrm{SiN}_{x}$ и диоксида кремния $\mathrm{SiO}_{2} ; 6$ - зеркальный алюминиевый слой; 7 компенсирующий слой (аналогичный обращенному опорному), состоящий последовательно из слоев диоксида и нитрида кремния. Стрелками условно изображены внутренние напряжения.
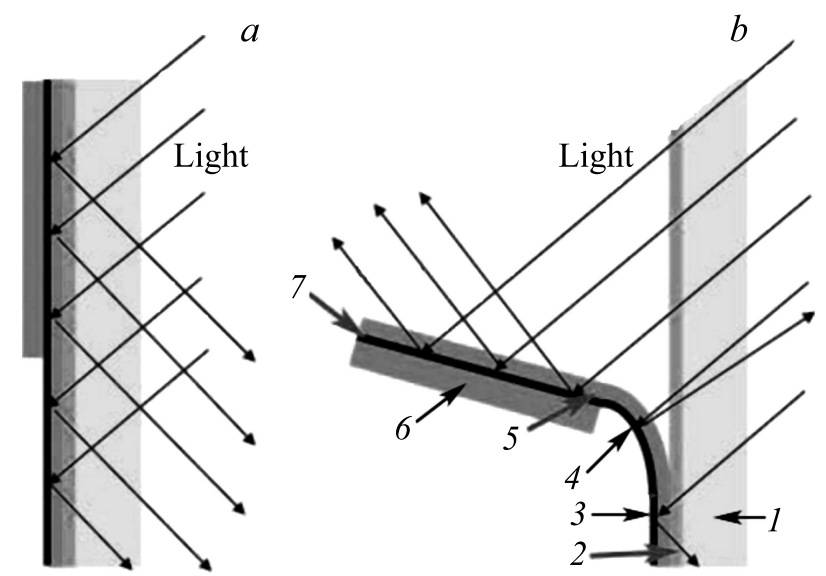

Pис. 25. Схема взаимодействия потока солнечного света с микрозеркалом в закрытом $(a)$ и открытом $(b)$ состояниях [35]: 1 - стекло; 2 - электроизолирующий слой нанесен на прозрачный электропроводящий слой; 3 - якорная часть, которая одновременно является элементом электрической цепи; 4 шарнирная часть; 5 - опорный слой (основа микрозеркала); 6 - компенсирующий слой; 7 - зеркальный алюминиевый слой.

некомпенсированных внутренних напряжений изгибается и микрозеркало отходит от стекла.

Теоретические расчеты показали, что под действием электростатических сил по мере увеличения напряжения от 0 до $80 \mathrm{~V}$ микрозеркало от начального положения с углом наклона к плоскости стекла $\sim 90^{\circ}$ контролируемо наклоняется к стеклу до угла $\sim 45^{\circ}[35,36]$. При дальнейшем увеличении напряжения микрозеркало неконтролируемо наклоняется к стеклу, закрывает его и фиксируется в этом положении. Однако экспериментально обеспечить промежуточные состояния микрозеркал с регулируемым наклоном от 90 до $45^{\circ}$ до настоящего времени не удается - реализуются только крайние состояния „открыто“ и „закрыто“. На рис. 22, $d$ при- ведено изображение массива микрозеркал в открытом положении.

Изготовлены опытные образцы массивов микрозеркал размером $100 \times 100 \mathrm{~mm}$. Размеры одного микрозеркала $150 \times 400 \mu \mathrm{m}$. На площадке размером $1 \mathrm{~mm}^{2}$ размещается около 12 микрозеркал, на образце $100 \times 100 \mathrm{~mm}-$ около 120000 таких элементов. На стекле площадью $1 \mathrm{~m}^{2}$ поместится 12000000 штук. Для того чтобы удерживать массив микрозеркал в закрытом состоянии, необходимо затрачивать электрическую мощность $1 \mathrm{~mW} / \mathrm{m}^{2}$. Светопропускание составляет $75 \%$ в открытом и $2 \%$ в закрытом состояниях.

Поскольку отдельные микропросветы глаз не различает, изображение при просмотре через образец с открытыми микрозеркалами не искажается, но массив микрозеркал равномерно затеняется подобно добавке тонкопленочного затеняющего покрытия. В открытом состоянии микрозеркала часть света проходит без изменения направления, другая часть перенаправляется на потолок и повышает равномерность освещения в помещении. Образец с закрытыми микрозеркалами практически не пропускает свет.

Единственный способ регулирования светопропускания состоит в изготовлении массива микрозеркал в виде избирательно активируемых рядов-субмассивов микрозеркал.

Микрожалюзи в обычном положении без электростатического воздействия имеют закрученную форму состояние „открыто“. При подключении напряжения под электростатическим воздействием они раскручиваются и переходят в плоское состояние - „закрыто“. Микрожалюзи не перенаправляют падающий свет на потолок. Возможно только изменение светопропускания за счет закрытия их части, что достигается в результате изготовления последовательности рядов микрожалюзи различного размера. Микрожалюзи в таких рядах закрываются под воздействием различного напряжения: чем больше размер микрожалюзи, тем больше величина необходимого для их закрытия напряжения [32,39].

Микрозеркала активируются электростатически и настолько мелки, что невооруженный глаз не может различить их по отдельности с расстояния более $0.20 \mathrm{~m}$, в результате создается впечатление однородной панели. Основные преимущества массива микрозеркал:

- высокая скорость переключения;

- низкое энергопотребление, которое значительно меньше, чем для других типов динамических стекол;

- свет не поглощается, но полностью отражается на потолок помещения или наружу, поэтому отсутствует нагрев стекла в отличие от термохромных и электрохромных устройств, основанных на поглощении излучения;

- они не изменяют спектр солнечного света, но отражают ближнее инфракрасное излучение слоем ITO;

- несмотря на использование механически подвижных элементов, срок эксплуатации велик вследствие их миниатюризации. 
Микрозеркала не могут полностью заменить конкурентные технологии переключаемых стекол или световых модуляторов. Однако для приложений, где существенное значение имеют скорость переключениямодуляции света, низкое энергопотребление, контраст, длительность эксплуатации и температурная устойчивость, они являются лучшим кандидатом.

Основной недостаток массива микрозеркал - ограничения на его размеры, которые накладывает используемая для изготовления достаточно сложная технология микроэлектронных систем. Максимальный реализованный размер модуля микрозеркал составляет $100 \times 100 \mathrm{~mm}$ [37]. Для увеличения размера динамических стекол такие модули объединяют в массивы. Совершенствование технологии приведет к постепенному увеличению размеров модулей микрозеркал и снижению их стоимости до величин, при которых их можно устанавливать для регулирования светового потока в окнах.

\section{4. Заключение}

Значительное сокращение электроэнергии и повышение равномерности освещенности достигаются при использовании в системах бокового естественного освещения размещаемых в верхней части окна оптических устройств с целью перенаправления солнечного света на отражающий потолок и вглубь помещения.

Первоначально предложенные оптические устройства обладают рядом недостатков, обусловленных их значительной массой и габаритами. В настоящее время проводятся исследования по совершенствованию оконных оптических устройств в направлении уменьшения их размеров с переходом на микроуровень Уменьшение размеров оптических структур не изменяет оптических свойств и позволяет избежать отклонения от законов геометрической оптики до тех пор, пока их размеры не достигают диапазона длины волны видимого света. Перевод оптических структур на микроуровень облегчает их внедрение в окна и уменьшает вызываемое ими визуальное воздействие.

Выполнены разработки и исследование трех видов оконных оптических микроструктур: микропризматических пленок, панелей с призматическими микроструктурами на двух сторонах, пленок с внедренными микрозеркалами. Стадии коммерческой реализации достигли разработки микропризматической пленки - она изготавливается по высокопроизводительной непрерывной технологии при перематывании с барабана на барабан (roll-to-roll - R2R), легко монтируется способом наклеивания на стекло, прошла натурные испытания. Микропризматическая пленка с искривленными поверхностями вместо плоских обеспечивает высокую равномерность потока перенаправляемого рассеиваемого солнечного света.

Специфическими свойствами обладают массивы микрозеркал и микрожалюзи - оптические микроэлектро- механические системы, изготавливаемые по технологии микроэлектроники. Однако технологические проблемы ограничивают геометрические размеры этих устройств.

Необходимы значительные усилия для доведения различных видов оконных оптических микроструктур до стадии коммерческой реализации. Можно надеяться, что данный обзор создает полное представление о текущем состоянии исследований в этой области и вызовет интерес к дальнейшему их расширению.

\section{Конфликт интересов}

Автор заявляет, что у него нет конфликта интересов.

\section{Список литературы}

[1] Ruck N., Aschehoug Ø., Aydinli S., Christoffersen J., Courret G., Edmonds I., Jakobiak R., Kischkoweit-Lopin M., Klinger M., Lee M., Michel L., Scartezzini J.L., Selkowitz S. Daylight in Buildings: A Source Book on Daylighting Systems and Components. A report of IEA SHC Task 21 / ECBCS Annex 29, July 2000. California, US: International Energy Agency. 2000. 262 p.

[2] Lorenz W. // Solar Energy. 2001. V. 70. P. 109-130. doi 10.1016/S0038-092X(00)00132-8

[3] Siteco Daylight Systems. Режим доступа: http://www.siteco. com/en/products/daylight-systems.html

[4] Hocheng H., HuangT.Y., Chou T.H., Yang W.H. // J. Achievements Materials Manufacturing Engineering. 2010. V. 43. N 1. P. 409-417.

[5] Hocheng H., Huang T.Y., Chou T.H., Yang W.H. // Energy \& Buildings. 2011. V. 43. P. 1011-1019. doi 10.1016/j.enbuild.2010.12.027

[6] Huang T.Y., Hocheng H., Chou T.H., Yang W.H., Ting C.J., Cheng K.Y., Hsieh C.W. // Energy \& Buildings. 2015. V. 90. P. 114-126. doi 10.1016/j.enbuild.2014.12.051

[7] Padiyath R. Daylight Redirecting Window Films // ESTCP Project EW-201014. Final Report. 3M Company. 66 p. September 2013.

https://www.serdp-estcp.org/Program-Areas/Energy-andWater/Energy/Conservation-and-Efficiency/ EW-201014

[8] Padiyath R., Hao B., Marttlla C.A. Hybrid light redirecting and light diffusing constructions. Patent US 8995059 B2. 2015.

[9] $3 \mathrm{M}^{\mathrm{TM}}$ Daylight Redirecting Film. Режим доступа: https://multimedia.3m.com/mws/media/1209715O/3mdaylight-redirecting-film.pdf

[10] Thanachareonkit A., Lee E.S., McNeil A. // LEUKOS: J. Illuminating Engineering Society North America. 2014. V. 10. P. 19-45. doi 10.1080/15502724.2014.837345

[11] McNeil A., Lee E.S., Jonsson J.C. // Building \& Environment. 2017. V. 113. P. 280-297. doi 10.1016/j.buildenv.2016.07.019

[12] Tian Z., Lei Y., Jonsson J.C. // Building Simulation. 2019. V. 12. P. 129-140. doi 10.1007/s12273-018-0487-z

[13] SGG LUMITOP ${ }^{\circledR}$. Saint-Gobain Glass. Режим доступа: www.saint-gobain-glass.com

[14] Walze G., Nitz P., Ell J., Georg A., Gombert A., Hossfeld W. // Solar Energy Materials \& Solar Cells. 2005. V. 89. P. 233-248. doi 10.1016/j.solmat.2004.11.016 
[15] Klammt S., Müller H., Neyer A. Advanced Daylighting by Micro Structured Components // Convention Proceedings of PLDC 2nd Global Lighting Design Convention, Berlin, 2009.

[16] Klammt S., Neyer A., Mueller H.F.O. // Solar Energy. 2012. V. 86. P. 1660-1666. doi 10.1016/j.solener.2012.02.034

[17] Jakubowsky M., Neyer A. // Energy Procedia. 2017. V. 122. P. 157-162. doi 10.1016/j.egypro.2017.07.338

[18] Mueller H.F.O. // J. Daylighting. 2019. V. 6. P. 52-59. doi $10.15627 /$ jd.2019.7

[19] Edmonds I.R. // Solar Energy Material \& Solar Cells. 1993. V. 29. P. 1-26. doi 10.1016/0927-0248(93)90088-K

[20] SOLARTRAN. Laser Cut Panel. Режим доступа: http://solartran.com.au/lasercutpanel.htm

[21] SerraGlaze ${ }^{\circledR}$ Daylight Redirecting Film. SerraLux Inc. Peжим доступа: http://serraluxinc.com/

[22] Milner P.J. Optical components for daylighting and other purposes. Patent US 6616285 B2. 2003.

[23] Milner P.J. The SERRAGLAZE window - a revolution in daylighting // Proceedings EPIC. 2002. P. 661-666. http://www.aivc.org/sites/default/files/members_area/ medias/pdf/Conf/2002/106_009\%20Milner.pdf

[24] Kostro A.G., Geiger M., Jolissaint N., Lazo M.A.G., Scartezzini J.-L., Leterrier Y., Schüler A.M. // Proceedings of SPIE. 2012. V. 8485:84850L. doi 10.1117/12.930476

[25] Gong J., Kostro A., Motamed A., Schueler A. // Solar Energy. 2016. V. 139. P. 412-425. doi 10.1016/j.solener.2016.10.012

[26] Gong J., Meyer F. D., Letterier Y., Kostro A., Schueler A. // Energy Procedia. 2017. V. 122. P. 763-768. doi 10.1016/j.egypro.2017.07.393

[27] Gong J., Delaunay A., Kostro A., Schüler A. // Microelectronic Engineering. 2018. V. 191. P. 48-53. doi 10.1016/j.mee.2018.01.032

[28] Hornbeck L.J. // Proc. SPIE. 1989. V. 1150. P. 86-102. doi $10.1117 / 12.962188$

[29] Canonica M.D., Zamkotsian F., Lanzon P., Noell W., Rooij N.D. // Optics Express. 2013. V. 21. P. 22400-22409. doi 10.1364/OE.21.022400

[30] Pizzi M., Koniachkine V., De Martiis O., Marbach R. // IEEE/LEOS International Conference on Optical MEMS. 2003. P. $173-174$. doi 10.1109/OMEMS.2003.1233521

[31] Hillmer H., Schmid J., Stadler I. Micromirror array. Patent US 7677742 B2. 2010.

[32] Lamontagne B., Py C. Microblinds and a method of fabrication thereof. Patent US 7684105 B2. 2010.

[33] Mori K., Misawa K., Ihida S., Takahashi T., Fujita H., Toshiyoshi H.A // IEEE Photonics Technology Letters. 2016. V. 28. P. 593-596. doi 10.1109/LPT.2016.2514299

[34] Lamontagne B., Fong N. R., Song I.-H., Ma P., Barrios P., Poitras D. // J. Micro/Nanolithography, MEMS and MOEMS. 2019. V. 18. N 4. 040900. doi 10.1117/1.JMM.18.4.040901

[35] Viereck V., Schwank A., Neumann U. // DBU Abschlussbericht, AZ 23717, Kassel. 2009.

[36] Viereck V., Jäkel A., Neumann U., Schwank A., Hillmer H., Schmid J. // International Solar Energy Society Conference Proceedings. SWC. 2011. Kassel, Germany. 2011. doi 10.18086/swc.2011.04.09

[37] Hillmer H., Al-Qargholi B., Khan M. M., Worapattrakul N., Wilke H., Woidt C., Tatzel A. // Jap. J. Appl. Physics. 2018. V. 57. 08PA07. doi 10.7567/JJAP.57.08PA07

[38] Worapattrakul N. // Ph.D. Dissertation. Kassel university press GmbH. 2017. 195 p. doi 10.19211/KUP9783737602792
[39] Floyd P.D., de Groot W.A. Switchable windows with MEMS shutters. Patent US 8724202 B2. 2014. 